\title{
Medievalista
}

\section{Ali se mudou a aventura... 0 imaginário mítico no pensamento de Luís Krus}

Ali se mudou a aventura... The mythical imaginary in Luís Krus' thought

\section{Carlos F. Clamote Carreto}

\section{(2) OpenEdition}

\section{Journals}

\section{Edição electrónica}

URL: http://journals.openedition.org/medievalista/1371

DOI: 10.4000/medievalista.1371

ISSN: 1646-740X

\section{Editora}

Instituto de Estudos Medievais - FCSH-UNL

\section{Refêrencia eletrónica}

Carlos F. Clamote Carreto, « Ali se mudou a aventura... O imaginário mítico no pensamento de Luís Krus », Medievalista [Online], 22 | 2017, posto online no dia 01 dezembro 2017, consultado no dia 03 maio 2019. URL : http://journals.openedition.org/medievalista/1371 ; DOI : 10.4000/ medievalista.1371 
Título / Title: Ali se mudou a aventura... O imaginário mítico no pensamento de Luís Krus

/ Ali se mudou a aventura... The mythical imaginary in Luís Krus' thought

Autor(es) / Author(s): Carlos F. Clamote Carreto

Universidade / University: Universidade Nova de Lisboa

Faculdade e Departamento / Unidade de Investigação - Faculty and Department /

Research Center: Faculdade de Ciências Sociais e Humanas, Departamento de Línguas,

Culturas e Literaturas Modernas / Instituto de Estudos de Literatura e Tradição

Código Postal / Postcode: 1069-061

Cidade / City: Lisboa

País / Country: Portugal

Email Institucional / Institutional email: ccarreto@fcsh.unl.pt

Fonte: Medievalista [Em linha]. Direc. Bernardo Vasconcelos e Sousa. Lisboa: IEM.

Disponível em:

http://www2.fcsh.unl.pt/iem/medievalista/ MEDIEVALISTA22/carreto2208.html

ISSN: 1646-740X

Data recepção do artigo / Received for publication: 24 de Janeiro de 2017

Data aceitação do artigo / Accepted in revised form: 11 de Maio 2017 


\section{Resumo}

De "A morte das fadas" (1985) ao estudo de "uma variante peninsular do mito de Melusina” (1994), passando pelas reflexões sobre "As origens lendárias dos condes de Trastâmara" (1992), o mito ecoa, de forma regular e lancinante, no pensamento de Luís Krus enquanto estrutura dinâmica à volta da qual se cria e organiza uma visão coesa do mundo. Ao reconhecer a importância retórica, antropológica e ideológica da narrativa ficcional para a legitimação da linhagem e a construção de um discurso sobre o passado, Luís Krus não se limitou a renovar profundamente o olhar da historiografia tradicional sobre a cultura e as mentalidades medievais. Reinventou o diálogo, tantas vezes interrompido, entre literatura, história e estudos sobre o imaginário (vejam-se "A cidade no imaginário medieval" de 1983 ou "O imaginário português e os medos do mar" de 1998), criando pontes entre pessoas, disciplinas, saberes, linguagens e metodologias que ainda hoje falta, em grande medida, cumprir.

Palavras-chave: Literatura Portuguesa Medieval; História e Mito; Livros de Linhagem; Luís Krus

\section{Abstract}

From "A morte das fadas" (1985) to the study of "uma variante peninsular do mito de Melusina" (1994), through the reflections on "As origens lendárias dos condes de Trastâmara" (1992), the myth - as a dynamic structure which creates and organizes an unified vision of the world - echoes repeatedly and obsessively in the thought of Luís Krus. Recognizing the rhetorical, anthropological and ideological importance of the fictional narrative for the legitimization of the lineage and the construction of a discourse on the past, Luís Krus has devoted not only his work to an important renewal of the traditional viewpoints of Portuguese Medieval Historiography. He has deeply reinvented the dialogue among Literature, History and Studies on the Imaginary (as, for example, "A cidade no imaginário medieval" [1983] or "O imaginário português e os medos do mar" [1998]) creating bridges through people, disciplines, knowledge, languages and methodologies that are still largely lacking today.

Keywords: Portuguese Medieval Literature; Myth and Literature; Royal Iberian Genealogy; Luís Krus

Medievalista online № 22 | Julho - Dezembro 2017 (c) IEM - Instituto de Estudos Medievais 2 www2.fcsh.unl.pt/iem/medievalista 


\title{
Ali se mudou a aventura... O imaginário mítico no pensamento de Luís Krus / Ali se mudou a aventura... The mythical imaginary in Luís Krus' thought
}

\author{
Carlos F. Clamote Carreto
}

Historiography is an especially good ground on which to consider the nature of narration and narrativity because it is here that our desire for the imaginary, the possible, must contest with the imperatives of the real, the actual. If we view narration and narrativity as the instruments by which the conflicting claims of the imaginary and the real are mediated, arbitrated, or resolved in a discourse, we begin to comprehend both the appeal of narrative and the grounds for refusing it. If putatively real events are represented in a non-narrative form, what kind of reality is it that offers itself, or is conceived to offer itself, to perception? What would a non-narrative representation of historical reality look like?

Hayden White ${ }^{1}$.

Ali se mudou a aventura, que estava de choro e de lagrimas e de gram lastima e amargura a toda a cristaidade, e tornô-se em toda ledice e em, todo goivo. Livro de Linhagens ${ }^{2}$.

\section{Mito e identidade narrativa}

De "A vivência medieval do tempo" (1982) a "Leituras profanas da festa sagrada" (1999), passando pela "morte das fadas: a lenda genealógica da Dama do Pé de Cabra" (1985) - artigo retomado e ampliado em 1999 com o título "Uma variante peninsular do mito de Melusina: a origem dos Haros nos Livro de Linhagens do conde Barcelos" - e

\footnotetext{
${ }^{1}$ WHITE, Hayden - "The Value of Narrativity in the Representation of Reality". Critical Inquiry 7, 1 (1980), pp. 8-9.

${ }^{2}$ LIVRO DE LINHAGENS DO CONDE D. PEDRO - Ed. crítica J. Mattoso. Portugaliae Monumenta Historica. Nova Série, vol. II/1. Lisboa: Academia de Ciências de Lisboa, 1980, 21G15, daqui em diante indicado como $L L$.
}

Medievalista online $N^{\circ} 22$ | Julho - Dezembro 2017 (c) IEM - Instituto de Estudos Medievais 3 www2.fcsh.unl.pt/iem/medievalista 
por estudos como "Celeiro e relíquias: o culto quatrocentista dos mártires de Marrocos e a devoção dos nus" (1984), “Os heróis da Reconquista a realeza sagrada medieval peninsular" (1989) ou "As origens lendárias dos condes de Trastâmara" (1992) ${ }^{3}$ sem esquecer naturalmente o lugar estruturante ocupado pelas reflexões desenvolvidas na sua tese doutoramento, nomeadamente nos capítulos consagrados ao Livro de Linhagens $(L L)$ como "teorização do destino ibérico" (p. 113-1424) e à herança troiana e bretã na formação da cristandade ibérica (p. 143-170), o mito ecoa, regular e lancinante, no pensamento de Luís Krus ${ }^{5}$. Não o mito entendido como simples narrativa modelar, ou exemplar, relativamente estanque e cristalizada, sujeita apenas a expectáveis variações no decorrer de uma complexa transmissão oral e manuscrita, e muito menos como mera fábula destinada a deleitar os homens e situando-se assim (na tradição veiculada, nomeadamente, pelas Etimologias de Isidoro de Sevilha) nos antípodas do discurso histórico, esse sim inteiramente orientado para a narratio rei gestae (Etym. I, 40), mas sim o mito considerado simultaneamente como narrativa cultural através da qual uma determinada comunidade dá forma e sentido às suas vivências e aspirações ${ }^{6}$ e enquanto sistema dinâmico à volta do qual se cria e organiza uma visão coesa do mundo. Uma forma ao mesmo tempo simples e infinitamente plástica, sempre disponível, que nessa sua capacidade de reconfigurar a relação com o real, através de um discurso constantemente investido e mediado por símbolos, arquétipos e imagens, é suscetível de integrar tensões e conflitos - sem, no entanto, os apagar ou denegar - e de redefinir,

\footnotetext{
${ }^{3}$ Os artigos referidos estão compilados em KRUS, L. - A construção do passado medieval. Textos inéditos e publicados. Lisboa: IEM, 2011.

${ }^{4}$ Reportamo-nos à versão editada em 1994 pela Fundação Calouste Gulbenkian na colecção "Textos Universitários de Ciências Sociais e Humanas" infelizmente esgotada: A concepção nobiliárquica do espaço ibérico. Geografia dos livros de linhagens portugueses (1280-1380).

${ }^{5}$ Esta centralidade do mito, associada a uma reflexão singular e globalizante sobre a ideologia do poder na Idade Média, é receonhecida e destacada por Bernardo Vasconcelos e Sousa e Isabel Beceiro Pita na sua homenagem conjunta a L. Krus: "Luís Krus (1954-2005). In Memoriam”. Hispania. Revista Española de Historia [Em linha] 222, vol. 66 (janeiro-abril de 2006), pp. 321-324 [Consultado a 27 de abril de 2017]. Disponível em http://hispania.revistas.csic.es/index.php/hispania/article/view/10/10. ISSN: 00182141. As reflexões desenvolvidas neste artigo aprofundam as observações apresentadas no Colóquio Poder, mitos e memórias na sociedade medieval: contributos de Luís Krus (Torre do Tombo/Faculdade de Ciências Sociais e Humanas/NOVA, 1-2 de outubro de 2015).

${ }^{6}$ Esta conceção ontológica do mito como necessidade inerente à experiência humana está patente tanto em Nietzsche ( $O$ nascimento da tragédia) como em autores como Michel Tournier (Le Vent paraclet. Paris: Folio, 1978, pp. 183-184), Paul Ricœur, Charles Taylor ou Alasdair MacIntire, entre outros.
}

Medievalista online № 22 | Julho - Dezembro 2017 (c) IEM - Instituto de Estudos Medievais 4 www2.fcsh.unl.pt/iem/medievalista 
numa geometria infinitamente variável do desejo, a relação de forças o seio da sociedade ${ }^{7}$.

Através da sua "pregnância simbólica" (Ernst Cassirer) e das ligações, ou conexões, subliminares - e tantas vezes paradoxais - que permite estabelecer, a narrativização da experiência através do mito (ou, melhor dizendo, o mito enquanto forma narrativa privilegiada que confere sentido à existência nas suas mais variadas e secretas dimensões) permite igualmente estruturar e dar consistência ao tempo, tornando a experiência do mundo legível ou compreensível, logo comunicável (ou partilhável) e objeto de uma hermenêutica. Apesar das críticas que possamos formular à conceção ética e ontológica da narrativa que percorre tanto a hermenêutica ricœuriana ${ }^{8}$ como algumas tendências importantes da psicologia construtivista (Bruner, Sarbin ou Óscar Gonçalves que fala de um "ser narrativo" que vive narrativamente" ${ }^{9}$ ou, mais recentemente, das neurociências ${ }^{10}$, e na condição de reconhecermos que existem diferenças substantivas entre a experiência e a narrativa, entre o real e a linguagem que o reconfigura, é hoje indesmentível o potencial epistemologicamente agregador ou reunificador que desempenha a narrativa no âmbito das ciências sociais e humanas (e não só) e sua importância na construção de uma identidade individual e coletiva de cuja transmissão e interpretação depende, em grande parte, a construção de uma memória pessoal ou cultural ${ }^{11}$.

\footnotetext{
${ }^{7}$ Esta abordagem profana do mito enquanto estrutura dinâmica é partilhada - embora com pressupostos teóricos e epistemológicos muito distintos - tanto por Ricœur através da sua interpretação do conceito de mimese em Aristóteles (ver Temps et récit I, por exemplo) como por Gilbert Durand (Les Structures anthropologiques de l'imaginaire. Paris: Dunot, 1992, p. 64) e muito dos seus discípulos nos domínios dos estudos sobre o imaginário (J. J. Wunenburger, Ph. Walter, J. Thomas, H. Godinho, etc.).

${ }^{8}$ RICOEUR, P. - Temps et récit I. Paris: Seuil, 1983; RICOEUR, P. - Soi-même comme un Autre. Paris: Seuil, 1996.

9 GONÇALVES, Óscar - Viver narrativamente. A psicologia como adjectivação da experiência. Coimbra: Quarteto, 2000.

${ }^{10}$ No seu mais recente ensaio, António Damásio aponta para a importância da dinâmica narrativa na construção das memórias e na constituição dos mapas cerebrais que organizam a nossa experiência, falando ainda de uma "autêntica obsessão" do cérebro em contar histórias (DAMÁSIO, A. - O sentimento de si. O corpo, a emoção e a neurobiologia da consciência. Lisboa: Europa-América, 2000, p. 221).

${ }^{11}$ Ver o recente artigo da investigadora finlandesa MERETOJA, Fianna - "Narrative and Human Experience: Ontology, Epistemology, and Ethics". New Literary Review 45, 1 (2014) pp. 89-109.
}

Medievalista online № 22 | Julho - Dezembro 2017 (c) IEM - Instituto de Estudos Medievais 5 www2.fcsh.unl.pt/iem/medievalista 
Nesta perspetiva - e Luís Krus teve claramente esta intuição -, deixa de fazer sentido operar uma distinção radical entre grandes e pequenas mitologias ${ }^{12}$, entre modelos clássicos, possuidores de uma tradição manuscrita relativamente controlável, e uma tradição oral sujeita a constantes metamorfoses, entre cultura erudita e cultura popular. No domínio da História - da filosofia da história, mais precisamente -, um dos mais acérrimos defensor do paradigma narrativo foi certamente Hayden Whyte que, num célebre artigo publicado em 1980 na revista americana Critical Inquiry "13 "The value of Narrativity in the Representation of Reality", afirma, depois de definir a narrativa como uma metacódigo (tal como Claude Lévi-Strauss já tivera definido o mito como uma metalinguagem em cuja gramática se inscreve a própria gramática das relações sociais assentes, em larga medida, nas estruturas de parentesco, reforçando assim a relação de isomorfismo que une constantemente entre linguagem e linhagem amplamente estudada por um antropólogo da literatura como Howard Bloch em finais dos anos $80^{14}$ ) que é através da sua narrativização que o real adquire um valor histórica e ideologicamente orientado, uma narrativa sendo tanto mais verdadeira quanto mais coesa se apresentar e tanto mais coesa quanto mais eficaz for a estratégia retórica conduzindo a um reforço das marcas autorais reunificadoras do discurso. Nos artigos há pouco citados, Luís Krus nunca refere Hayden White nem Paul Ricœur. No entanto, é manifesta a sua sensibilidade antropológica ${ }^{15}$ e a atenção permanente ao discurso como construção retórica visando legitimar um nome, uma linhagem ou as aspirações de um grupo social (como a nobreza de Entre Douro e Minho, por exemplo), ou seja, visando construir uma memória através da reconfiguração narrativa do tempo e dos factos num processo hermenêutico que transcende a falsa dialética entre o ficção e o real e uma ainda mais problemática hierarquização das fontes artificialmente separadas entre fontes poético-

\footnotetext{
${ }^{12}$ A este propósito, ver as pertinentes reflexões de BOYER, Régis - "Petite mythologie: qu'est-ce à dire", in BAYARD, F.; GUILLAUME, A. (dir.) - Formes et difformités médiévales. Hommage à Claude Lecouteux. Paris: PUPS, 2010, pp. 63-74.

${ }^{13}$ Vol. 7, 1, pp. 5-27.

${ }^{14}$ BLOCH, H. - Etymologie et généalogie: une anthropologie littéraire du Moyen Âge français. Paris: Seuil, 1989 (a edição americana data de 1983).

${ }^{15}$ Como sublinha Jean-Jacques Vincensini ("Médiévistique et anthopologie". in VALETTE, J.-R. (dir.) Perspectives médiévales. Trente ans de recherches en langues et en littératures médiévales. Paris: Société de Langues et de Littératures Médiévales d'Oc et d'Oïl, 2005, pp. 447-467), o século XXI, por razões históricas e culturais, convida-nos cada vez mais a reconhecermos a importância de uma abordagem verdadeiramente antropológica para perscrutarmos e melhor compreendermos a alteridade constitutiva do período medieval. Entre nós, os estudos de L. Krus constituem certamente um marco determinante mo aprofundamento deste necessário e fecundo estreitamento de relações entre História, Literatura e Antropologia.
}

Medievalista online № 22 | Julho - Dezembro 2017 @ IEM - Instituto de Estudos Medievais 6 www2.fcsh.unl.pt/iem/medievalista 
literárias e documentos históricos ${ }^{16}$. Desde a sua tese de doutoramento que todo o esforço historiográfico de Luís Krus se concentra precisamente em demonstrar que a um discurso aparentemente fragmentário e heterogéneo que vê sucederem-se, ao logo de contínuas refundições, mais de 4.000 nomes oriundos de 776 famílias fidalgas, corresponde, na realidade, uma narrativa extremamente coesa, tanto do ponto de vista da tradição textual na qual se insere, como do ponto de vista simbólico e ideológico, erguendo assim à dimensão de mythos os Livros de Linhagem, a função que neles desempenham os vários mitos clássicos (voltaremos a esta questão) funcionando especularmente como um dispositivo ficcional que reforça esta dimensão textual. A natureza da fonte analisada convidava, é certo, a uma abordagem deste tipo, Luís Krus prolongando e aprofundando, através da sua exegese, a lógica subjacente à escrita do LL: com efeito, subordinando a inventio textual à prática da compilação (segundo o prólogo, dom Pedro compôs o seu livro depois de "catar por gram trabalho, por muitas terras, escrituras que falavam dos linguagees”), não pretendia já o conde de Barcelos dar uma configuração narrativa a testemunhos díspares e dispersos (nos espaço como no tempo) na qual a nobreza se pudesse re-conhecer e reunir em torno de uma memória e de um destino comuns?

As suas fecundas reflexões sobre os minúsculos Anais de Lorvão, nos quais vê a “memória legitimadora da comunidade monástica onde foram escritos e uma defesa dos seus direitos na situação conflitual em que os monges se viram no princípio do século XII" ${ }^{17}$ convergem metodologicamente com as de Hayden White quando, a propósito dos Anais de são Galo mostra que o aparente grau zero de narratividade característico deste género historiográfico marcado por uma conceção paratática do tempo (por oposição à construção hipotática da crónica ou dos escritos genealógicos que procuram inscrever "nos logares u convem " o nome numa vaste sintaxe do mundo que remonta à

\footnotetext{
16 "Désormais, [l'historiographie] doit être envisagée non seulement dans son contenu mais comme le miroir des mentalités, reflétant l'homme en représentation, pris dans les contradictions de son Moi et de son siècle. Les recherches menées [...] peuvent donc se répartir en deux grands axes. Les uns ont privilégié l'examen des formes qu'adopte l'historiographie pour s'adapter aux différents modes de pensée. Les autres ont considéré les textes comme un système herméneutique qui touche à la fois des questions philosophiques, anthropologiques et idéologiques" (GAUCHER, E. - "Historiographie". in VALETTE, J.-R. (dir.) - Perspectives médiévales. Trente ans de recherches en langues et en littératures médiévales. Paris: Société de Langues et de Littératures Médiévales d'Oc et d'Oïl, 2005, pp. 191-211, p. 191). Pela sua abrangência e abertura, o pensamento de L. Krus situar-se-ia certamente neste segundo eixo da investigação historiográfica.

${ }^{17}$ MATTOSO, José - "Prefácio". in KRUS, L. - A construção do passado medieval, p. 13.
}

Medievalista online № 22 | Julho - Dezembro 2017 ๑ IEM - Instituto de Estudos Medievais 7 www2.fcsh.unl.pt/iem/medievalista 
Criação) traduz, na verdade, a presença de uma comunidade textual capaz de preencher os hiatos e a existência de um princípio de narratividade onde o não-dito (a lacuna, as elipses) é tão ou mais eloquente do que os factos assinalados, e onde a ausência de marcas autorais reflete a existência de uma auctoritas imanente à própria escrita que se dissolve ao longo da Idade Média, implicando, como testemunha frequentemente o próprio $L L$, o reforço dos dispositivos gramaticais que conferem uma articulação temporal e lógica ao discurso acompanhado de uma reforço da presença autoral ${ }^{18}$.

Luís Krus não deixa de insistir neste aspeto crucial: positivo ou negativo, apológico ou crítico, a narrativa não só veicula valores como cria valores e modelos - muitas vezes ficcionais - de comportamento ${ }^{19}$.

\section{Apenas veredas e iluminações pontuais... ${ }^{20}$}

Ao reconhecer a importância retórica, antropológica e ideológica da narrativa (seja ela ficcional ou não) para a legitimação da linhagem e a construção de um discurso sobre o passado, Luís Krus não se limitou a renovar profundamente o olhar da historiografia tradicional sobre a cultura e as mentalidades medievais. Reinventou o diálogo, tantas vezes interrompido, entre literatura, história e estudos sobre o imaginário, criando pontes entre pessoas, disciplinas, saberes, linguagens e metodologias que ainda hoje falta, em grande medida, cumprir. O alerta e o desafio que nos lança no início do seu

\footnotetext{
18 Transformação que se manifesta exemplarmente na passagem do verso à prosa nas ficções em torno do Graal a partir do século XIII.

19 Pela sua natureza cronográfica, e não só, vislumbra-se no Livro de Linhagens uma conceção agostiniana do tempo e da representação onde a narrativa como textum a decifrar volta a assumir um papel central. Recordemos, com efeito, que na sua leitura do mito genesíaco, Santo Agostinho joga constantemente com a homonímia que une as vestes que cobrem o corpo do casal primordial e o pergaminho das Sagradas Escrituras, ambos designados pelo vocábulo pellis; pele essa que simultaneamente nos afasta da plena Presença de Deus e que dela nos aproxima através da exegese das syllabas temporum da linguagem humana (AGOSTINHO DE HIPONA - Confissões. Ed. bilingue (Latim/Português) Arnaldo do Espírito Santo; João Beato; Maria Cristina de Castro-Maia de Sousa Pimentel e introdução de Manuel Barbosa da Costa Freitas. Lisboa: INCM, 2000, XXX). Numa outra passagem (AGOSTINHO DE HIPONA - Confissões, XIII, 24), estabelece claramente a relação de isomorfismo entre dispersão genealogia e dispersão semântica (com as ambiguidades inerentes à palavra humana) que parecem traduzir um mesmo exílio semiológico e simbólico, sendo o caminho do regresso apontando tanto pelo trabalho exegético do bispo de Hipona como pelo ambicioso projeto de reunificação das linhagens nobres proposto pelo conde D. Pedro de Barcelos: "Por meio desta bênção, concedei-nos o poder e a licença de enunciar de diversos modos o que o nosso espírito concebe duma maneira simples, e de perceber sob várias formas o que nos Vossos Livros lemos enunciado, obscuramente, duma só maneira. É assim que se povoam "as águas do mar", que não se moveriam sem estas diversas interpretações. É assim que as várias gerações dos homens enchem a terra, cuja aridez se fertiliza pela paixão da verdade, sob o domínio da razão".

${ }^{20}$ KRUS, L. - “Apresentação". in Passado, Memória e Poder na Sociedade Medieval Portuguesa. Estudos. Redondo: Patrimomia, 1994, p. 20.
}

Medievalista online № 22 | Julho - Dezembro 2017 (c) IEM - Instituto de Estudos Medievais 8 www2.fcsh.unl.pt/iem/medievalista 
artigo "Uma variante peninsular do mito de Melusina" é bastante eloquente ao evocar nomeadamente "a existência de certos preconceitos epistemológicos-metodológicos que, relegando as fontes literárias para os domínios da fantasia e da curiosidade, não estimulam a [...] abordagem histórica" (p. 151) de certas narrativas como a Dama do Pé de Cabra. Não admira, neste sentido, que Luís Krus tenha dado particular importância aos modelos ficcionais na construção ou reconfiguração da identidade linhagística: a par do modelo teológico subjacente à tradição cronográfica na esteira de Eusébio de Cesareia e Orósio de $\mathrm{Braga}^{21}$ enquanto macroestrutura temporal que preside à organização do nobiliário, reconhece ainda a pregnância de dois modelos narrativos concorrenciais na legitimação das aspirações da nobreza: o modelo épico e o modelo romanesco. Na esteira de medievalistas como Dominique Boutet ou Armand Strubel ${ }^{22}$, por exemplo, reconhece implicitamente a relação de consubstancialidade - e não de simples mimese especular - que une consciência histórica e forma literária, a canção de gesta insinuando-se, por exemplo, como uma matriz narrativa que envolve uma visão do mundo alternativa em relação àquela que oferece o romance antigo ou arturiano, por exemplo $^{23}$. A ficção surge então como um poderoso dispositivo capaz de criar uma imagem homogénea das aspirações de determinados grupos sociais (a velha nobreza, a burguesia ou a categoria dos juvenes em busca de uma terra longínqua e de "um espaço

\footnotetext{
${ }^{21}$ No espaço peninsular, este modelo continua a transparecer no Liber Regum (ou Chronicon Villarense), composto em Navarra por volta do ano 1200 e no Libro de las Generaciones, materiais que serviram à composição do Nobiliário do Conde D. Pedro cujo projeto se demarca assim do enunciado nos prólogos do Livro Velho de Linhagens e do Livro de Deão que limitavam os seus respetivos universos aos "bons homens filhos d'algo do reino de Portugal". O $L L$ integra-se então plenamente no paradigma linguísticogenealógico e temporal que temos vindo a esboçar. Note-se, de resto, que subjacente a esta conceção corresponde necessariamente, não uma obra fechada, mas uma escrita em constante devir, uma verdadeira estética do inacabamento que faz da contínua recriação um processo consubstancial à composição do livro: "E rogo aaqueles que depois de mim veerem e vontade houverem de saber os linhagees, que acrecentem em estes titolos deste livro aqueles que adiante decenderem dos nobres fidalgos da Espanha, e os ponham e escrevam nos logares u convem" ("Prólogo". in LIVRO DE LINHAGENS DO CONDE D. PEDRO).

${ }^{22}$ BOUTET, D.; STRUBEL, A. - Littérature, politique et société dans la France du Moyen Âge. Paris: PUF, 1979. (com prefácio de J. le Goff); BOUTET, D. - "Mythe, littérature et société". in HARFLANCNER, L.; BOUTET, D. (dir.) - Pour une mythologie du Moyen Âge. Paris: École normale supérieure des jeunes filles, 1988, pp. 89-97; BOUTET, D. - Formes littéraires et conscience historique. Aux origines de la littérature française 1100-1250. Paris: PUF, 1999.

${ }^{23}$ Sem falarmos, claro está, das outras importantes formas narrativas de cunho mais paródico ou satírico como o Roman de Renart ou os fabliaux que alargam consideravelmente a geografia do poder da corte às ordens monásticas, passando pelos novos atores da civilização mercantil e urbana (burgueses, comerciantes, etc.). Contudo, estas formas narrativas, fortemente imbuídas de um imaginário carnavalesco, não poderiam naturalmente servir de modelo num projeto de registo grave e austero como o que preside os $L L$.
}

Medievalista online № 22 | Julho - Dezembro 2017 ๑ IEM - Instituto de Estudos Medievais 9 www2.fcsh.unl.pt/iem/medievalista 
de aventura" 24 onde possam construir a sua glória e afirmar a sua identidade, como refere insistentemente Luís Krus a propósito da elaboração da matéria de Bretanha nas cortes principescas do século XII seguindo, neste ponto, as teses sociológicas defendidas por Erich Köhler nos anos $70^{25}$ ), embora incessantemente percorrida pela tensão entre o real e o ideal, entre o tempo das coisas e o tempo da representação. Na sua brevíssima introdução (em jeito de roteiro) à sua tese de doutoramento, assenta, de resto, a sua interpretação do Livro de Linhagens numa constato simples mas que acaba por moldar decisivamente tanto a sua leitura da obra como a metodologia utilizada. Com efeito, afirmar que o esquema narrativo que preside à construção do $L L$ (esquema ampliado nos anos 1380-1383 pelo último dos refundidores) consiste em atribuir "à fidalguia de Portugal a qualidade de aristocracia guerreira peninsular", a filiação simultaneamente visigótica e adâmica da nobreza predestinando-a a ser "milícia de Cristo a quem estaria reservada a proteção e salvação de toda a Cristandade” (p. 16), equivale a reconhecer a pregnância do modelo épico (com o seu fundo hagiográfico ${ }^{26}$ ) na representação deste grupo social. E reconhecer a pregnância do modelo épico implica, por sua vez, reconhecer - aspeto hoje consensual entre os medievistas - a pregnância de um imaginário mítico ancestral (frequentemente um mito fundador associado à batalha como momento que inaugura uma nova ordem) ${ }^{27}$ que simultaneamente estrutura e desestrutura o discurso ideologicamente orientado da História. Na esteira da herança assumida por Georges Duby e por Jacques Le Goff, transparecem na análise que Luís Krus faz de várias narrativas do $L L$ os contributos da mitologia comparada, nomeadamente através do papel dinâmico desempenhado pela matriz indo-europeia na construção narrativa do destino épico-heroico dos guerreiros peninsulares. Dos muitos exemplos possíveis, citemos apenas a influência dos estudos de Joël Grisward (Archéologie de l'épopée médiévale de $1981^{28}$ ) e de Georges Dumézil

\footnotetext{
${ }^{24}$ KRUS, L. - A concepção nobiliárquica do espaço ibérico, p. 153.

${ }^{25} \mathrm{E}$ KÖHLER, E. - L'Aventure chevaleresque. Idéal et réalité dans le roman courtois. Études sur la forme des plus anciens poèmes d'Arthur et du Graal. Paris: NRF-Gallimard, 1974 (a tradução francesa foi, também ela, prefaciada por Jacques Le Goff).

${ }^{26}$ Ver BOUTET, D. - La Chanson de geste. Forme et signification d'une écriture épique au Moyen Âge. Paris: PUF, 1993, pp. 34-64.

${ }^{27}$ Ver, por exemplo, as considerações de Ph. Walter: "l'épopée romane raconte l'histoire d'un mythe ou un mythe historicisé. Il ne faut pas voir en elle l'écho d'une quelconque réalité historique (elle vit d'anachronismes permanents), mais un prisme déformant où l'on reconnait les reflets conjugués de l'Histoire et du Mythe" (WALTER, Ph. - Naissances de la littérature française: IX ${ }^{e}-X V^{e}$ siècle: anthologie. Grenoble: ELLUG, 1998, p. 55).

${ }^{28}$ Paris: Payot, 1981 (prefácio de Georges Dumézil).
}

Medievalista online $N^{\circ} 22$ | Julho - Dezembro 2017 ๑ IEM - Instituto de Estudos Medievais 10 www2.fcsh.unl.pt/iem/medievalista 
(L’Idéologie tripartite des Indo-Européens de 1958, Mythe et épopée II de 1971) cujas reflexões e metodologia - a par dos contributos da antropologia estrutural (Mauss, LeviStrauss, Polanyi) através da qual demonstra, por exemplo, que a destruição de Troia radica na rutura simbólica implicada na quebra dos laços de hospitalidade (p. 145) marcam indelevelmente o seu capítulo sobre a translatio imperii et studii da mitologia troaina e bretã para o espaço peninsular em torno desse novo e paradoxal Édipo que se perfila sob o rosto de Brutus (p. 149-152). Como também marcam a sua minuciosa interpretação das aventuras hispânicas de Hércules no artigo sobre "Os heróis da Reconquista e a realeza sagrada medieval peninsular" na Primeira Crónica Geral de Espanha onde a relação entre mito, construção da memória e legitimação do poder desagua numa perspicaz reflexão sobre o imaginário mitopoético da cidade na Idade Média $^{29}$ em que a posse da terra e a fundação da urbe fazem ecoar - mesmo que sob a forma eufemística de um sonho mântico - mitos arcaicos ligado à união incestuosa e hierogâmica com a Deusa-Mãe ${ }^{30}$, e em que vemos a rivalidade política (entre o Papa Gregório X e Afonso X, nomeadamente) assumir claramente os traço de uma rivalidade entre modelos míticos em constante tensão. Finalmente, é ainda e sempre a perspetiva dumeziliana da mitologia comparada (Le Problème des centaures, de 1929, citado na página 157, ou Heurs et malheurs du guerrier. Aspects de la fonction guerrière chez les Indoeuropéens, de 1970, citado na pagina 159) que orienta, no seu estudo sobre "Uma variante peninsular do mito de Melusina: a origem dos Haros no Livro de Linhagens do conde de Barcelos", a sua particularmente hábil leitura das três narrativas do $L L$ (A independência da Biscaia, a Dama do Pé de Cabra e a História do Cavalo Pardalo) centradas em torno do motivo da fada ao qual voltaremos.

\footnotetext{
${ }^{29}$ Provavelmente influenciadas pelos trabalhos de Jacques Le Goff (ver, por exemplo, o interessante artigo "Jérusalem ou Babylone? L'image de la ville dans la littérature française médiévale" publicado na revista Critique em 1978), as reflexões de L. Krus e o destaque que nelas é dada ao papel determinante da chamada Matéria Antiga (ou de Roma) - Roman d'Alexandre, Roman de Thèbes, Roman d'Eneas, Roman de Troie - na formação do imaginário medieval da cidade antecipam vários trabalhos que virão, anos mais tarde, a ser realizados neste domínio: BAUMGARTNER, E.; HARF-LANCNER, L. (dir.) - Entre fiction et histoire: Troie et Rome au Moyen Âge. Paris: Presses de la Sorbonne Nouvelle, 1997; CROIZYNAQUET, C. - Thèbes, Troie et Carthage. Poétique de la ville dans le roman antique au XII siècle. Paris: Honoré Champion, 1994.

${ }^{30}$ Referimo-nos à passagem $(P C G$ 9) em Júlio César, dormindo no palácio de Hispano, "teve a visão de uma relação incestuosa mantida com a mãe, à qual, depois de interpretada pelo seu astrólogo, foi dada o seguinte sentido: a mãe era a terra, e tal como dela se apoderara assim dominaria toda a orbe e seria senhor de tudo" ("Os heróis da Reconquista", p. 122).
}

Medievalista online № 22 | Julho - Dezembro 2017 ( ) IEM - Instituto de Estudos Medievais 11 www2.fcsh.unl.pt/iem/medievalista 
Esta postura metodológica e epistemológica de extrema abertura interdisciplinar perante as fontes conduzem naturalmente Luís Krus a apontar sub-repticiamente para as diversas camadas ou fragmentos míticos que estruturam, em profundidade, a narrativa genealógica. O seu intuito não consiste em analisá-las pormenorizadamente - aspetos que poria forçosamente em causa a própria coesão e homogeneidade do seu discurso. Mas aponta para preciosos, e em larga medida ainda inexplorados, caminhos para a crítica literária. No seu conjunto, estas valiosas pistas são decerto - como ele próprio humildemente dizia no prefácio à coletânea de artigos intitulada Passado, memória e poder na sociedade medieval - "apenas veredas e iluminações pontuais de uma paisagem ainda mal percorrida e desvendada nos seus diversos contornos e elementos constituintes" (p. 20). Não deixam, no entanto, de revelar perspicácia, admirável intuição e partilha generosa por parte um espírito intelectualmente fecundo, inquieto e metodologicamente rigoroso embora inconformado. Na sua tese de doutoramento, Luís Krus sugere assim uma interessante analogia entre o destino do Rei Rodrigo (pp. 113114), que foi "perdudo [...] e nom o acharom mais" (LL 3D1, 3C15, 3D3, 3D36, 3E1) e o do rei Artur da Bretanha, morto à traição por Mordech, filho do pecado secreto (o incesto cometido com a irmã ou meia-irmã, segundo as variantes), e transportado para Islavalom, esse Outro-Mundo da mitologia celta governado pelas Fadas do qual não há vêm notícias "se é vivo, se é morto" ( $L L$ 2E3). Através desta mitema do rei ferido e oculto, o simbolismo arcaico da alternância cíclica conflui agora com o sentido escatológico e messiânico que as narrativas de linhagem procuram dar à realeza heroica. Por sua vez, a condenação, pelo conte dom Pedro, da morte de Lopo Dias, um dos chefe mais proeminentes da prestigiada linhagem dos Haros, pelo seu soberano, D. Sancho de Castela, em Alfarro, é sagazmente interpretada por Luís Krus como uma reação àquilo que configura, no ethos épico, uma verdadeira "desordem dos tempos" (p. 119), uma violação do pacto feudal de solidariedade entre a realeza e os bellatores que introduz uma rutura na sintaxe linhagística representando uma autêntica agressão simbólica à Ordem do Mundo. E é novamente esta mesma ordem do mundo que volta a estar implicada na sua belíssima análise da Batalha do Salado, nomeadamente no contraste entre a exortação à vitória dos cavaleiros cristãos (exemplarmente construída do ponto de vista retórico) $)^{31}$ e o planctus do derrotado rei de Marrocos, figuração simbólica do

31 "Senhores, este é o nosso dia, em que havemos de escarecer, e este é o dia da vitoria e da honra dos

Medievalista online № 22 | Julho - Dezembro 2017 ( ) IEM - Instituto de Estudos Medievais 12 www2.fcsh.unl.pt/iem/medievalista 
Rei Velho cujo nome parece não mais ter lugar na gramática do universo, dando lugar a uma nova geração de heróis solares: "Ai velho, hoje perdiste o teu nome que havia em toda Eiropa, em toda Africa, e em Asia." (LL 21G15). Do outro lado do espelho ideológico e textual, este lamento, que denuncia uma falha profunda na função soberana, não deixa de relembrar o estranho cansaço que Carlos Magno (figura convenientemente apagada dos $L L$ ) manifesta no final da Chanson de Roland quendo é impelido, pela voz do arcanjo Gabriel, a travar uma nova batalha em prol da Cristandade. Mas não é este o único indício intertextual a que as passagens narrativas pertinentemente seleccionadas por Luís Krus nos convidam a explorar. Ainda no episódio do Salado, numa altura em que as forças dos cavaleiros desfalecem nos limiares de uma morte anunciada, eis que surge em todo o seu esplendor por entre o hostil exército dos Mouros, um cavaleiro transportando a Vera Cruz:

Ali se mudou a Aventura, que estava de choro e de lagrimas e de gram lastima e amargura a toda a cristaidade, e tornô-se em toda ledice e em, todo goivo. (LL 21G15)

Importa salientar que o Santo Lenho, que "lançava de si raios de fogo", "esprandecia como o sol", a milícia de Cristo surgindo, aos olhos dos Mouros, sob os traços de "grandes gigantes" dos mitos de fundação ${ }^{32}$ que "semalhavam diaboos do inferno" ( $L L$ 21G15). Nesta valorização hiperbólica do guerreiro cristão, que passa por uma reiterada e sempre ambígua inversão da polaridade semântica das imagens, ecoa novamente o modelo rolandiano, a regeneração solar das forças heróicas assemelhando-se ao milagre do sol que se imobiliza na Chanson de Roland permitindo a vitória dos Cristãos sobre as hostes do rei Baligant e na qual Joël Grisward ${ }^{33}$ vira a manifestação de um subestrutura mítica de contornos claramente cósmicos.

\footnotetext{
fidalgos. Este é o dia da salvaçom de nossas molheres e filhos e daqueles que de nós decenderem. E Este é o dia em que havemos semelhar nossos avoos, que ganharoom a Espanha" (LL 21G15).

32 Tal como em algumas narrativas bíblicas (Génesis, 6, 4; Números, 13, 33), na tradição arturiana, o reino de Logres é primitivamente povoado por gigantes. Será esta comparação dos cavaleiros cristãos a gigantes uma forma de erguer os feitos dos guerreiros peninsulares a um regresso regenerador às origens dos tempos?

${ }^{33}$ GRISWARD, J. - "Le "soleil arrêté" de la Chanson de Roland et le "soleil trestorné" de Hervis de Mes (Histoires de Soleils II)". in GUILLOT, C.; HEIDEN, S.; PRÉVOST, S. (dir.) - À la quête du sens. Études littéraires, historiques et linguistiques en hommage à Christiane Marchello-Nizia. Lyon: ENS Éditions (Langages), 2006, pp. 303-312.
}

Medievalista online № 22 | Julho - Dezembro 2017 @ IEM - Instituto de Estudos Medievais 13 www2.fcsh.unl.pt/iem/medievalista 


\section{O Mito e o Tempo}

A sensibilidade literária de Luís Krus torna-o, de resto, particularmente atento ao mais ínfimo motivo, entendido não como imagem estereotipa ou cristalizada na e pela tradição, mas como micronarrativa saturada de sentido: aspeto que se destaca nas suas breves, embora extremamente sugestivas, digressões sobre o bestiário fantástico do Livro de Linhagens (a serpente que irrompe no meio do combate entre Artur e Mordech [LL, 2E3], os leões e os camelos aos quais são comparados respetivamente os mártires cristãos da Batalha do Salado e os seus cavalos) ou de alguns objetos maravilhosos, como essa espada empunhada por Gonçalo Mendes da Maia (pp. 116-117) e cujos golpes eram tão devastadores que "nom podiam seer dados por homees" ( $L L, 21 \mathrm{G} 6)$. Pela sua natureza e estatuto singulares, encarnando a presença divina na tessitura da própria linguagem, a Vera Cruz ocupa expectavelmente um lugar de destaque por entre estes objetos com poderes mágicos e legitimadores. A este propósito, Luís Krus desenha subtilmente os contornos de duas personagens antitéticas, o imperador Constantino e Cosdroe, o rei mago, através das quais se vislumbram as diferenças - ou tensões - entre dois modelos de conhecimento (a ciência de origem divina por oposição à ciência pagã da nigromancia), dois modelos de representação e duas visões do mundo que dão conta, em última análise, das progressivas mutações culturais e epistemológicas que acompanham os últimos séculos da Idade Média. Com efeito, nos antípodas do reino cristão legitimado por Deus, a fonte $(L L, 3 C 20)$ situa o soberano persa - cuja presença é recorrente na canção de gesta francesa, nomeadamente no microciclo narrativo em torno de Vivien, o sobrinho do famoso guerreiro carolíngio Guilherme de Orange - nos confins geográficos do universo conhecido, ou seja, nos limiares entre dois mundos. Em posse da Vera Cruz, eis que Cosdroe manda construir "um céu d'arame e sol e lua e estrelas, e fazia chover per encantamento". Por detrás do fascínio discreto que exercem sobre os autores medievais as maravilhas do Oriente repleto de autómatos, exemplarmente analisada por Luís Krus na sua geografia contrastiva do imaginário da Europa, África e Ásia no Livro de Linhagens que segue, nesta matéria, o modelo literário da chamada Matéria Antiga (ou de Roma) inaugurada pela versão anglonormanda do Romance de Alexandre (pp. 143-170) - matéria que Luís Krus demonstra conhecer na perfeição -, vislumbra-se aqui toda a diferença entre o Milagre e o Simulacro, entre a "presença relicária das coisas nas palavras" na qual se funda, 
segundo Howard $\mathrm{Bloch}^{34}$, a natureza idealmente performativa da linguagem no paradigma épico e da qual depende a coesão da comunidade textual ${ }^{35}$ a que se destina, e um maravilho profano, totalmente mecanizado e ineficaz que procura em vão dominar os ciclos cósmicos, entre o tempo da Criação e o tempo do artifício $^{36}$. A diferença abismal, em suma, entre o poder do imaginário simbólico que reivindica e no qual se reconhece a nobreza medieval dos $L L$ e o falso poder demiúrgico, infinitamente manipulável e instrumentalizável, mas profundamente ilusório, dos signos.

Esta evolução semiológica, cultural e antropológica está de resto, a meu ver, no centro do pensamento de Luís Krus. A começar pelos seus trabalhos sobre as Inquirições Gerais de Afonso III ao concluir que, "em contraste com as origens míticas e intemporais que se atribuíam à nobreza, e que fundamentavam, em parte, aos olhos dos camponeses dependentes, o seu real poder, os inquiridores, ao querem saber qual o rei que beneficiou tais famílias, contribuem para uma diminuição do seu poder simbólico" 37 . Face a uma memória construída, enraizada e constantemente legitimada nesse vasto reservatório simbólico da tradição mítica cuja dimensão predominantemente oral é hoje unanimemente (re)conhecida, emerge assim, através das inquirições, o poder centralizador e totalizante de uma cultura urbana alicerçada na escrita, na força autolegitimadora da prova documental que lança progressivamente uma sombra de desconfiança sobre uma transmissão puramente oral $^{38}$.

Um outro estudo extremamente revelador a este propósito, no qual Luís Krus volta, de resto, a evidenciar plenamente a sua dívida intelectual para com a abordagem antropológica, consiste na sua original análise da procissão dos nus entre o século XIII e

\footnotetext{
${ }^{34}$ BLOCH, H. - Etymologie et généalogie, pp. 135-136.

${ }^{35}$ Sobre esta noção, ver STOCK, B. - The Implications of Literacy. Written Language and Models of Interpretation in the Eleventh and Twelfth Centuries. Princeton: Princeton University, 1983, pp. 88-240.

${ }^{36}$ Sobre os autómatos como "engin à suspendre le temps" (função simbólico e cósmica que encontramos em vários poemas medievais - Le Pèlerinage de Charlemagne à Jérusalem, Floire et Blancheflor, Le Bâtard de Bouillon, por exemplo), ver BAUMGARTNER, E. - "Le temps des automates". in Le Nombre du temps. En Hommage à Paul Zumthor. Paris: Champion, 1988, pp. 15-21; LEGROS, H. "Connaissance, Réception et perceptions des automates orientaux au XII siècle". in CHANDÈS, G. (dir.) - Le Merveilleux et la magie dans la littérature. Amsterdam/Atlanta: 1992, pp. 103-136.

${ }^{37}$ KRUS, L. - "A vivência medieval do tempo". in A construção do passado medieval, p. 30.

${ }^{38}$ No domínio ficcional, desta viragem dão conta, por exemplo, vários prólogos de romance e de canção de gesta quando procuram enraizar a sua auctoritas na imagem (ou miragem) do livro que mantém e consagra, inviolada, a integridade da história (estoire) face à exações dos jograis que incansavelmente a corrompem e a dispersam nos meandros da fábula.
}

Medievalista online № 22 | Julho - Dezembro 2017 @ IEM - Instituto de Estudos Medievais 15 www2.fcsh.unl.pt/iem/medievalista 
a altura da sua proibição formal no século XVIII $^{39}$ através da qual põe claramente em evidência a relação de isomorfismo entre um contexto marcado pela seca, a forme e a peste e a ressurgência de um culto arcaico, de natureza agrária, onde a exibição da nudez se liga ao rituais da virilidade e da fecundidade associados frequentemente ao solstício de Inverno. Neste contexto, a sua interdição em 1798 pelo bispo-conde de Coimbra D. Francisco de Lemos Pereira Coutinho, não revela apenas uma mutação profunda na sensibilidade social em contexto claramente urbano. Traduz, num espaçotempo marcado pelo paradigma da razão, do progresso (p. 148) e da lógica discursiva, um profundo distanciamento face à memória e ao sentido primitivos de um mito - agora obscuro e ilegível - no qual se inscrevia a inextricável aliança entre os ciclos da natureza e a vida social.

A tensão ou rivalidade entre imaginário mítico-simbólico e ideologia do signo que promovem conceções distintas do mundo e do poder, inscreve-se finalmente no centro das reflexões de Luís Krus sobre a origem mítica dos Haros no Livro de Linhagens do conde de Barcelos, o estudo, a meu ver, o mais representativo da sua extrema abertura epistemológica. Na sua minuciosa e audaz exploração das três narrativas que configuram, a montante como a jusante da tradição textual, o mito melusiniano da Dama do Pé de Cabra reivindica simultaneamente os contributos da historiografia nas suas diversas correntes, sensibilidades e opções metodológicas (José Mattoso, Jacques Le Goff, Emmanuel Ladurie, Georges Duby), da etnografia espanhola (Julio Caro Baroja, José Miguel de Barandiarán), da mitologia comparada (Georges Dumézil, Claude Lecouteux), dos estudos literários (Martín de Riquer, Menendez-Pidal, Carlos Alvar e os trabalhos de Laurence Harf-Lancner sobre as fadas na Idade Média) e dos estudos sobre o imaginário (Gilbert Durand) para tentar trazer alguma luz sobre os meandros de uma lenda particularmente rica e complexa do ponto de vista simbólico, explicar as razões que presidiram à sua inscrição num contexto textual e ideológico preciso, e compreender os motivos que levaram à transformação e ao desaparecimento da figura da fada em versões mais tardias (século XV). De forma inovadora para a época (as primeiras versões do artigo datam de 1985), pelo menos entre nós, Luís Krus

\footnotetext{
${ }^{39}$ KRUS, L. - "Celeiro e relíquias: o culto quatrocentista dos mártires de Marrocos e a devoção dos nus". in A Construção do passado medieval, pp. 133-149.
}

Medievalista online № 22 | Julho - Dezembro 2017 ( ) IEM - Instituto de Estudos Medievais 16 www2.fcsh.unl.pt/iem/medievalista 
procede assim a uma verdadeira antropologia histórica do maravilhoso ${ }^{40}$ através de uma metodologia muito próxima da que é seguida pela mitocrítica. Destaque-se, por exemplo e sem entrar em todos os pormenores, a análise do vasto complexo simbólico ligado a ritos sacrificiais (o tributo da vaca, do boi e do cavalo brancos na narrativa da Independência da Biscaia; a fundação da linhagem associada à fecundação da terra pelo sangue; o ritual propiciatório da refeição noturna em honra das fadas); a dialética entre o interdito e sua transgressão em torno da qual se organiza o mito melusiniano e onde a Dama do Pé de Cabra, figura emblemática ligada à fecundidade, é providencialmente encontrada na sequência de perseguição iniciática a um animal psicopompo que prefigura, em inúmeras narrativas de fundo indo-europeu, o acesso à soberania (o javali) ${ }^{41}$; o culto cavalar que estrutura a narrativa do Cavalo Pardalo associada aos ritos da "Deusa-Mãe pré-histórica, com a qual os reis celtas se acasalavam uma vez por ano em troca de prosperidade para o seu povo" 42 e à mitologia do ferro que Luis Krus relaciona, na esteira de Georges Dumézil e Gilbert Durand ${ }^{43}$, com a função guerreira, mas que estudos recentes ${ }^{44}$ ligam primordialmente a ritos nupciais e, por conseguinte, à terceira função.

Ao comparar a versão da genealogia dos Haros recolhida pelo conde de Barcelos versão na qual ainda se refletem, nomeadamente através das anamorfoses da fada, as influências da matéria da Bretanha cultivada na corte de Henrique II Plantageneta e Eleonor da Aquitânia - com a versão consagrada na Crónica de Vizcaya de Lope García de Salazar (1454), Luís Krus dá ainda conta de vários fenómenos importantes. Em primeiro lugar, uma tendência à domesticação do mundo feérico, as narrativas tendendo,

\footnotetext{
${ }^{40}$ Ver o recente ensaio de Laurent Guyénot cujo título faz providencialmente eco ao da segunda versão do estudo de L. Krus (“A morte das fadas: a lenda genealógica da Dama do Pé de Cabra” publicado em 1985 na revista Ler História): GUYENOT, L. - La Mort féérique. Anthropologie du merveilleux - XII ${ }^{e}-X V^{e}$ siècle. Paris: NRF-Gallimard, 2011.

${ }^{41}$ WALTER, Ph. (dir.) - Mythologies du porc (Actes du colloque de Saint-Antoine l'Abbaye, Isère, 4-5 avril 1998). Grenoble: Éditions Jérôme Million, 1999.

${ }^{42}$ KRUS, L. - "Uma variante peninsular do mito de melusina", p. 158.

43 É a propósito da mitologia cavalar no contexto da épica francesa que L. Krus ("Uma variante peninsular do mito de melusina”, p. 161, nota 23) cita a obra pioneira de DURAND, G. - Les Structures anthropologiques de l'imaginaire publicada em 1960 (DURAND, G. - Les Structures anthopologiques de l'imaginaire. Paris: Dunot, 1992).

${ }^{44}$ Sobre as personagens equídeas na literatura medieval, ver WALTER, Ph. - "Le pied de la lettre et les pieds de l'incube: sur une leçon du manuscrit de Bonn". in GODINHO, H.; ALPALHÃO, M.; CARRETO, C.; BARROS DIAS, I. (dir.) - Da Letra ao Imaginário. Homenagem à Professora Irene Freire Nunes. Lisboa: FCSH/CEIL, 2013, pp. 39-54. Sobre a mitologia do ferro ligada ao imaginário equestre, ver as recentes reflexões do mesmo autor na sua recente obra sobre a figura de Gauvain: WALTER, Ph. - Gauvain, le chevalier solaire. Paris: Imago, 2013, pp. 182-214.
}

Medievalista online № 22 | Julho - Dezembro 2017 (c) IEM - Instituto de Estudos Medievais 17 www2.fcsh.unl.pt/iem/medievalista 
com o passar dos anos, a exorcizar o que de ameaçador (porque tornadas parcialmente ininteligível) tinham essas figuras evocando divindades silvestres e aquáticas primitivas, íncubos e súcubos, comportavam para os letrados de trezentos. Na versão transmitida por García de Salazar, a fada desaparece, pura e simplesmente, do horizonte da narrativa, sendo substituída por uma inócua e estereotipada princesa de Gales que troca confortavelmente a floresta pelo solar. A duas versões representam assim, segundo a bela expressão de Luís Krus, "dois capítulos de uma gramática do poder" (p. 162) no centro da qual o mito, a sua apropriação e transformação, desempenha sempre um papel crucial.

Em segundo lugar, demonstra - e este é um aspeto metodologicamente relevante - que a relação entre o Mito e discurso do poder não conta necessariamente a história de uma relação unívoca e pacífica de apropriação ideológica do material mitológico ou lendário. A associação entre Brutus e Édipo, a assimilação do bretão Balduc, o Voador, a Ícaro ( $L L, 2 C 9)$, bem como os excessos e a desmesura apontados a figura tais como Membriz ou Morpidus, passando pelos já referidos pecados segredos do rei Artur, mostravam claramente que, por oposição ao hipervalorizado modelo épico, o modelo romanesco funciona simultaneamente como a matriz positiva (é a partir dela, constata Luís Krus na sua tese de doutoramento, que o Livro de Linhagens desenha a geografia europeia, nomeadamente ${ }^{45}$ ) e negativa, a Matéria de Roma e o romance de cavalaria espelhando, de certo modo, a imagem de uma realeza franca (os Plantageneta) que "constituía para a narrativa a grande força política interessada na quebra da unidade hispânica” (p. 170); um espelho perante a narrativa do conde Barcelos e dos seus refundidores tinha, por conseguinte, de manter alguma distância crítica e protetora. Da mesma forma, verificamos que tanto a versão da lenda da Dama do Pé de Cabra transmitida pelo nobiliário, como a narrativa que explica, na mesma fonte, as origens míticas dos condes de Trastâmara através da figura de D. Froão que casara com uma molher marinha ${ }^{46}$, ou as versões francesas transmitidas por Jean d'Arras (Le Roman de Mélusine, circa 1393) e Coudrette (inícios do século XV), exibem uma constante tensão entre o mundo feérico e o mundo do herói, entre o tempo do mito e o tempo da narrativa, a ordem social e a

\footnotetext{
${ }^{45}$ Sobre esta questão, ver o capítulo 6, KRUS, L. - "Da Europa troiana e bretã à cristandade ibérica". in $A$ concepção nobiliárquica do espaço ibérico, pp. 143-170.

${ }^{46}$ Ver o estudo de KRUS, L. - "As origens lendárias dos condes de Trastâmara". in A construção do passado medieval, pp. 181-278.
}

Medievalista online № 22 | Julho - Dezembro 2017 @ IEM - Instituto de Estudos Medievais 18 www2.fcsh.unl.pt/iem/medievalista 
ordem cósmica, cujo equilíbrio depende sempre de cedências mútuas e de uma delicada e frágil gestão dos limites.

Em terceiro e último lugar, a forma como Luís Krus aborda a questão do imaginário (um conceito operativo que, na esteira de G. Durand e de G. Duby ${ }^{47}$, não repudia utilizar para designar esse espesso filtro imagético e cultural que preside aos fenómenos de representação ${ }^{48}$ ) reveste-se de uma particular importância para o estudo dos mitos. Com efeito, embora reconheça a existência de um "illo tempore mítico" ${ }^{49}$, ou seja, a pregnância de mitemas que se transmitem, com poucas variações, ao longo da tradição, o principal contributo de Luís Krus (que deveria ser também, de resto, o principal objetivo de uma análise mitocrítica rigorosa) reside em mostrar que o mito, enquanto forma narrativa que encarna no tempo, é, antes de mais, um "molde ficcional [...] historicizável" 50 cujo sentido depende de um contexto de inscrição. Para se tornar verdadeiramente narrativa identitária eficaz suscetível de construir, mesmo que ficcionalmente, a memória de uma determinada comunidade textual, o mito tem de insinuar-se como lugar de confluência privilegiado - senão único - entre o real (a inscrição de nomes próprios ou toponímicos concretos numa sintaxe temporal e vivencial), o imaginário e a linguagem. Assim se desenha uma "geografia imperfeita" 51 em que a construção territorial e social do poder assenta igualmente numa transformadora poética da linhagem. Daí a constante atenção de Luís Krus aos mais ínfimos pormenores lexicais através dos quais se mede, por exemplo, a distância que separa uma identidade coletiva idealizada da imagem negativizada do Outro: veja-se, explica Luís Krus na sua tese de doutoramento, a radical diferença entre a terminologia que caracteriza a entrada violenta, usurpadora e destruidora dos romanos na península,

\footnotetext{
${ }^{47}$ Pensamos, claro está, na célebre obra As três ordens ou o imaginário do feudalismo de 1978.

${ }^{48}$ KRUS, L. - "A cidade no imaginário medieval". Diário de Notícias, Suplemento História, Lisboa, 29 de Março de 1983; KRUS, L. - "O imaginário português e os medos do mar". in NOVAES, Adauto (org.) - A descoberta do homem e do mundo, São Paulo, Ministério da Cultura - Fundação Nacional de Arte Companhia das Letras, 1998, pp. 95-105. Na sua tese de doutoramento, o conceito emerge essencialmente no espaço mais aberto a novas pistas e relações interdisciplinares constituído pelo aparato crítico das notas de rodapé: na página 125 (nota 259), por exemplo, evoca assim o imaginário da riqueza que caracteriza a Ásia do $L L$, falando, na página 146 (nota 314), de um "imaginário disciplinador dos jovens da corte" a propósito da reutilização do tema da guerra de Troia.

${ }^{49}$ KRUS, L. - "Uma variante peninsular do mito de Melusina", p. 170.

${ }^{50}$ KRUS, L. - "Uma variante peninsular do mito de Melusina", p. 157.

${ }^{51}$ DACOSTA, A. - "Geografías imperfectas: linaje y poder en la obra de L. Krus". Medievalista [Em linha] 20 (Julho - Dezembro 2016). [Consultado a 27 de abril de 2017]. Disponível em http://www2.fcsh.unl.pt/iem/medievalista/MEDIEVALISTA20/dacosta2002.html. ISSN 1646-740X
}

Medievalista online № 22 | Julho - Dezembro 2017 ( ) IEM - Instituto de Estudos Medievais 19 www2.fcsh.unl.pt/iem/medievalista 
face ao léxico que descreve a presença dos godos ("entrar", "andar", "estar") como se estes fossem parte integrante do território hispânico. Neste sentido, se o mito é um imenso reservatório de sentido, um significante do desejo ou uma forma simples, na terminologia de André Jolles ${ }^{52}$, sempre disponível, este sentido só é libertado e só se torna verdadeiramente inteligível quando é reinvestido, com finalidades identitárias ou políticos concretas, por sujeitos igualmente concretos, num determinado momento histórico, ideológico e cultural. Só assim se evitam generalizações metodologicamente duvidosas ou olhares redutores igualmente duvidosos. Só assim se pode compreender, por outro lado, por que razão um narrativa mítica é reivindicada por um autor ou uma comunidade social e rejeitado por outra e, por outro lado, por que motivo um dado mito ressurge num determinado contexto temporal e geográfico para desaparecer num contexto diferente que virá a exumar outras matrizes ficcionais consideradas, consciente ou inconscientemente, como mais aptas a traduzir os seus anseios, sonhos ou aspirações. Só assim se explica finalmente a lógica secreta que leva autores, compiladores ou refundidores da Idade Média a reunirem, numa mesma narrativa, fragmentos míticos díspares e oriundos de tradições distintas em detrimento de outros num complexo jogo poético, simbólico e ideológico tecido de opções mais ou menos secretas ou discretas, de silêncios cúmplices e de rivalidades latentes, de lacunas, hiatos e rasuras sobre os quais apenas nos é permitido formular conjeturas. Uma coisa é, no entanto, certa: nos aventurosos e incertos caminhos que ligam a voz do mito à lição do texto, Luís Krus soube desbravar fronteiras, sugerir sentidos, inspirar leituras e iluminar veredas que, na confluência de vários saberes e metodologias, muito têm ainda por explorar e desvendar.

\footnotetext{
${ }^{52}$ JOLLES, A. - Formes simples. Paris: Seuil, 1972.
}

Medievalista online № 22 | Julho - Dezembro 2017 ( IEM - Instituto de Estudos Medievais 20 www2.fcsh.unl.pt/iem/medievalista 


\section{Referências bibliográficas:}

\section{Fontes impressas}

AGOSTINHO DE HIPONA - Confissões. Ed. bilingue (Latim/Português) Arnaldo do Espírito Santo; João Beato; Maria Cristina de Castro-Maia de Sousa Pimentel e introdução de Manuel Barbosa da Costa Freitas. Lisboa: INCM, 2000.

ISIDORO DE SEVILHA - Etimologias. 2 vols. Ed. bilingue (Latim/Espanhol) J. Oroz Reta; M. A. Marcos Casquero. Madrid: BAC, 1982.

JACQUES DE VITRY - Histoire de l'Occident (Historia occidentalis). Trad. Francesa de G. Duchet-Suchaux, com introdução e notas de J. Longère. Paris: les Éditions du Cerf, 1997.

LIVRO DE LINHAGENS DO CONDE D. PEDRO. Ed. crítica J. Mattoso. Portugaliae Monumenta Historica. Nova Série, vol. II/1. Lisboa: Academia de Ciências de Lisboa, 1980.

\section{Estudos}

BAUMGARTNER, E. - "Le temps des automates". in Le Nombre du temps. En Hommage à Paul Zumthor. Paris: Champion, 1988, pp. 15-21.

BAUMGARTNER, E.; HARF-LANCNER, L. (dir.) - Entre fiction et histoire: Troie et Rome au Moyen Âge. Paris: Presses de la Sorbonne Nouvelle, 1997.

BOUTET, D. - "Mythe, littérature et société". in HARF-LANCNER, L.; BOUTET, D. (dir.) - Pour une mythologie du Moyen Âge. Paris: École normale supérieure des jeunes filles, 1988, pp. 89-97.

- La Chanson de geste. Forme et signification d'une écriture épique au Moyen Âge. Paris: PUF, 1993. 
- Formes littéraires et conscience historique. Aux origines de la littérature française 1100-1250. Paris: PUF, 1999.

- ; STRUBEL, A. - Littérature, politique et société dans la France du Moyen Âge. Paris: PUF, 1979.

BOYER, R. - "Petite mythologie, qu'est à dire?". in BAYARD, F.; GUILLAUME, A. (dir.) - Formes et difformités médiévales. Hommage à Claude Lecouteux. Paris: PUPS, 2010, pp. 63-74.

BLOCH, H. - Etymologie et généalogie: une anthropologie littéraire du Moyen Âge français. Paris: Seuil, 1989.

CROIZY-NAQUET, C. - Thèbes, Troie et Carthage. Poétique de la ville dans le roman antique au XII siècle. Paris: Honoré Champion, 1994.

DACOSTA, A. - "Geografías imperfectas: linaje y poder en la obra de Luís Krus". Medievalista [Em linha] 20 (Julho - Dezembro 2016). [Consultado a 27 de abril de 2017]. Disponível em

http://www2.fcsh.unl.pt/iem/medievalista/MEDIEVALISTA20/dacosta2002.html. ISSN 1646-740X

DAMÁSIO, A. - O sentimento de si. O corpo, a emoção e a neurobiologia da consciência. Lisboa: Europa-América, 2000.

DUMEZIL, G. - L'Idéologie tripartite des Indo-Européens. Latomus, 1958.

- Mythe et épopée. Paris: Gallimard, 1995.

DURAND, G. - Les Structures anthopologiques de l'imaginaire. Paris: Dunot, 1992. 
GAUCHER, E. - "Historiographie". in VALETTE, J.-R. (dir.) - Perspectives médiévales. Trente ans de recherches en langues et en littératures médiévales. Paris: Société de Langues et de Littératures Médiévales d'Oc et d'Oïl, 2005, pp. 191-211.

GONÇALVES, O. - Viver narrativamente. A psicologia como adjectivação da experiência. Coimbra: Quarteto, 2000.

GRISWARD, J. - Archéologie de l'épopée médiévale. Paris: Payot, 1981.

- "Le "soleil arrêté" de la Chanson de Roland et le "soleil trestorné" de Hervis de Mes (Histoires de Soleils II)". in GUILLOT, C.; HEIDEN, S.; PRÉVOST, S. (dir.) - À la quête du sens. Études littéraires, historiques et linguistiques en hommage à Christiane Marchello-Nizia. Lyon: ENS Éditions (Langages), 2006, pp. 303-312.

GUYENOT, L. - La Mort féérique. Anthropologie du merveilleux - XII ${ }^{e}-X V^{e}$ siècle. Paris: NRF-Gallimard, 2011.

JOLLES, A. - Formes simples. Paris: Seuil, 1972.

KÖHLER, E. - L'Aventure chevaleresque. Idéal et réalité dans le roman courtois. Études sur la forme des plus anciens poèmes d'Arthur et du Graal. Paris: NRFGallimard, 1974.

KRUS, L. - “A cidade no imaginário medieval”. Diário de Notícias, Suplemento História, Lisboa, 29 de Março de 1983.

- A concepção nobiliárquica do espaço ibérico. Geografia dos Livros de Linhagens portugueses (1280-1380). Lisboa: Fundação Calouste Gulbenkian, 1994.

- "O imaginário português e os medos do mar". in NOVAES, Adauto (org.) - A descoberta do homem e do mundo, São Paulo, Ministério da Cultura - Fundação Nacional de Arte - Companhia das Letras, 1998, pp. 95-105.

Medievalista online $N^{\circ} 22$ | Julho - Dezembro 2017 ( ) IEM - Instituto de Estudos Medievais 23 www2.fcsh.unl.pt/iem/medievalista 
- A construção do passado medieval. Textos inéditos e publicados. Lisboa: INCM, 2011.

LE GOFF, J. - Les Trois ordres ou l'imaginaire du féodalisme. Paris: Gallimard, 1978.

- "Babylone ou Jérusalem: la ville dans l'imaginaire collectif au Moyen Âge". Critique 373-374 (1978), pp. 554-559.

LEGROS, H. - "Connaissance, Réception et perceptions des automates orientaux au XII ${ }^{\mathrm{e}}$ siècle". in CHANDÈS, G. (dir.) - Le Merveilleux et la magie dans la littérature. Amsterdam/Atlanta: 1992, pp. 103-136.

MATTOSO, José - "Prefácio". in KRUS, L. - A construção do passado medieval. Textos inéditos e publicados. Lisboa: INCM, 2011.

MERETOJA, F. - "Narrative and Human Experience: Ontology, Epistemology, and Ethics”. New Literary Review 45, 1 (2014), pp. 89-109.

RICEEUR, P. - Temps et récit I. Paris: Seuil, 1983.

- Soi-même comme un Autre. Paris: Seuil, 1990.

STOCK, B. - The Implications of Literacy. Written Language and Models of Interpretation in the Eleventh and Twelfth Centuries. Princeton: Princeton University, 1983.

TOURNIER, M. - Le Vent paraclet. Paris: Folio, 1978.

VASCONCELOS E SOUSA, B.; BECEIRO PITA, I. - "Luís Krus (1954-2005). In Memoriam”. Hispania. Revista Española de Historia [Em linha] 222, vol. 66 (janeiroabril de 2006), pp. 321-324 [Consultado a 27 de abril de 2017].

Disponível em http://hispania.revistas.csic.es/index.php/hispania/article/view/10/10. ISSN: 0018-2141.

Medievalista online $N^{\circ} 22$ | Julho - Dezembro 2017 ( ) IEM - Instituto de Estudos Medievais 24 www2.fcsh.unl.pt/iem/medievalista 
VINCENSINI, J.-J. - "Médiévistique et anthopologie". in VALETTE, J.-R. (dir.) Perspectives médiévales. Trente ans de recherches en langues et en littératures médiévales. Paris: Société de Langues et de Littératures Médiévales d'Oc et d'Oïl, 2005, pp. 447-467.

WALTER, Ph. - Naissances de la littérature française: IX $X^{e}-X V^{e}$ siècle: anthologie. Grenoble: ELLUG, 1998.

- (dir.) - Mythologies du porc (Actes du colloque de Saint-Antoine l'Abbaye, Isère, 4-5 avril 1998). Grenoble: Éditions Jérôme Million, 1999.

- Gauvain, le chevalier solaire. Paris: Imago, 2013.

- "Le pied de la lettre et les pieds de l'incube: sur une leçon du manuscrit de Bonn". in GODINHO, H.; ALPALHÃO, M.; CARRETO, C.; BARROS DIAS, I. (dir.) - Da Letra ao Imaginário. Homenagem à Professora Irene Freire Nunes. Lisboa: FCSH/CEIL, 2013, pp. 39-54.

WHITE, H. - "The Value of Narrativity in the Representation of Reality". Critical Inquery 7,1 (1980), pp. 5-27.

\section{COMO CITAR ESTE ARTIGO}

\section{Referência electrónica:}

CARRETO, Carlos Clamote - "Ali se mudou a aventura... o imaginário mítico no pensamento de Luís Krus ”. Medievalista 22 (Julho-Dezembro 2017). [Em linha] [Consultado dd.mm.aaaa]. Disponível em http://www2.fcsh.unl.pt/iem/medievalista/MEDIEVALISTA22/carreto2208.html ISSN 1646-740X.

Medievalista online $N^{\circ} 22$ | Julho - Dezembro 2017 ( ) IEM - Instituto de Estudos Medievais 25 www2.fcsh.unl.pt/iem/medievalista 


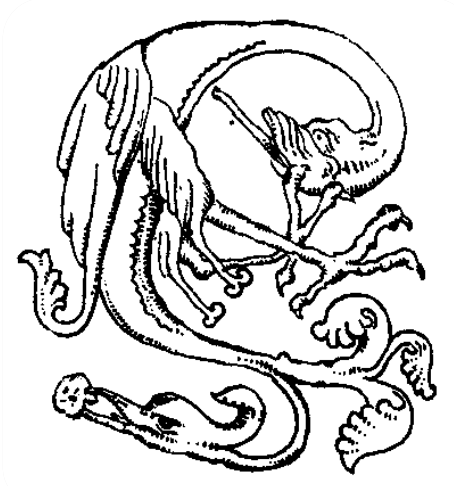

